\title{
On the Determination of Levelized Cost of Electricity of Wind Energy in the Coastal Areas of Bangladesh
}

\author{
Fahmida Azmi ${ }^{1}$, M. Mofazzal Hossain ${ }^{2}$ \\ ${ }^{1}$ Department of Computer Science and Engineering, East West University, Dhaka, Bangladesh \\ ${ }^{2}$ Department of Electronics and Communications Engineering, East West University, Dhaka, Bangladesh
}

Email address:

fazmi@ewubd.edu (F. Azmi),dmmh@ewubd.edu (M. M. Hossain)

\section{To cite this article:}

Fahmida Azmi, M. Mofazzal Hossain. On the Determination of Levelized Cost of Electricity of Wind Energy in the Coastal Areas of Bangladesh. Journal of Electrical and Electronic Engineering. Vol. 5, No. 2, 2017, pp. 74-79. doi: 10.11648/j.jeee.20170502.18

Received: February 19, 2017; Accepted: March 1, 2017; Published: April 13, 2017

\begin{abstract}
Sustainable energy supply is the key to industrial, social and economic developments of any society. At the same time environment friendly sustainable energy supply is a burning issue nowadays. Among other renewable energy sources, due to geographical location, wind energy harvesting is more prospective in Bangladesh, especially in the coastal area of Bangladesh. In this work we studied the feasibility of harvesting wind energy in the coastal area of Bangladesh through the calculation of levelized cost of electricity (LCOE) at seven different locations. It is found that among seven locations the LCOE is approximately $5 \mathrm{BDT} / \mathrm{kWh}$ at Kuakata and St. Martin. We also investigated the effects of blade diameter and tower height on LCOE. It is found that the minimum LCOE may be achieved using blade diameter of $21.5 \mathrm{~m}$ and tower height has insignificant effects on the LCOE of wind energy for the coastal area of Bangladesh.
\end{abstract}

Keywords: LCOE, Renewable Energy, Wind Energy, Tower Height, Blade Diameter

\section{Introduction}

The Energy is an indispensable part of human life and modern civilization. Sustainable energy supply is the key to industrial, social and economic developments of any society. Without sustainable energy, the survival of mankind would be impossible. Among different forms of energy, the most consumed and useful form of energy is electricity. Still today, most of the industrialized and developing countries depend on fossil fuels like oil, natural gas and coal to generate electricity. Moreover, fossil fuels used in transportation and industries, produces greenhouse gases. It is established that the major greenhouse gas emitters are the electricity generation plants. According to IEA (International Energy Agency) report the greenhouse gas emission from power plants in 2050 will be increased by $130 \%$ that of in 2005 [12]. The greenhouse gases in turn, are mainly responsible for the global warming which is a burning issue to combat. Conventional fossil fuel recourses are limited and demand of energy is growing up day by day. Moreover, it is proven that there are several remote areas where connection to the public electric grid are not cost effective or feasible [3]. Another issue is to reduce the electricity transmission and distribution losses which is more than $33 \%$ in Bangladesh [4-5]. The amount of $\mathrm{CO}_{2}$ has increased from $280 \mathrm{ppm}$ to $400 \mathrm{ppm}$ in the atmosphere since early in the 19th Century [6]. It is estimated that the amount of $\mathrm{CO}_{2}$ emission will increase more dramatically in the next 20 years if we continue to use fossil fuel for energy production. If the world stays on the current path of increasing emissions, it is possible that global temperature could increase by approximately 1 to 3.5 degrees Celsius. Many impacts of climate change have already been observed, including melting of the iceberg in north pole, increasing sea level, flood in several cities, drought and heat wave in several cities, changes in the timing of seasonal events and changes in agricultural productivity such as inland flooding, extreme weather events, food insecurity, and the loss of marine and coastal ecosystems and biodiversity [7].

All these issues of concerning to fossil fuel and their impact on the environment can be easily be addressed by using renewable energy sources. It is technically feasible for renewable energy technologies to replace the present fossil fuel based electricity generation infrastructure $[8,9]$. However, the economic barriers remain the primary impediment to a renewable energy based society [10]. 
Enthusiastically, around the globe, the awareness has already been developed to combat all these issues, and the renewable energy sources like wind, solar, and hydro become popular gradually. For Bangladesh, wind energy is prospective, as throughout the year minimum wind velocity is $3.35 \mathrm{~m} / \mathrm{s}$, and monthly wind velocity is $4.54 \mathrm{~m} / \mathrm{s}$ to $4.79 \mathrm{~m} / \mathrm{s}$ at a height of $25 \mathrm{~m}$ especially in the coastal area of Bangladesh [11-13].

Feasibility of wind energy is site dependent and is especially suitable for coastal areas (both onshore and offshore). However, the setup of wind turbine system in offshore locations is more time consuming and expensive compare to onshore location. Therefore, in this paper focus is pointed on the onshore wind energy system. Due to the manufacturing maturity of wind turbine system, the efficiency of wind power system increased in the last decades. Therefore, the use of wind energy conversion system in the coastal areas where the wind velocity has a reasonable value to generate electricity is a prime concern in a developing country like Bangladesh. In this paper, we predicted the LCOE of wind energy conversion and investigated the dependence of LCOE on blade diameter and tower height at different locations in the coastal areas of Bangladesh.

\section{Prospects of Wind Energy in Bangladesh}

Bangladesh is one of the most densely populated countries in world with the population of 160 million [14]. The population is increasing and as a result the demand of electricity is also increasing gradually. The electricity generation in Bangladesh using conventional fossil fuel and renewable energy sources are presented in Fig. 1 [15].

According to the Bangladesh power development board Bangladesh (BPDB), generation capacity of Bangladesh is 12185 MW. Nearly $62 \%$ of the total power is generated from natural gas, which is found in eastern zone of Bangladesh. The next largest source of power generation is furnace oil which is followed by diesel and coal. However, this is not enough to serve the total population of Bangladesh. Only $58 \%$ of the population has access to electricity with a per capita availability of $285 \mathrm{kWh}$ per annum [16]. Moreover, natural gas reserve will be ceased by next 50 years. Therefore, to meet the demand for electricity is a prime concern for Bangladesh. In this situation using renewable energy can be a very suitable alternative for electricity generation. Moreover, renewable sources are fuel free and environmental friendly. Bangladesh is producing a small amount of hydroelectric power in Karnafuli river in Kaptai. There are some private companies which use solar and wind energy but those are very insignificant.

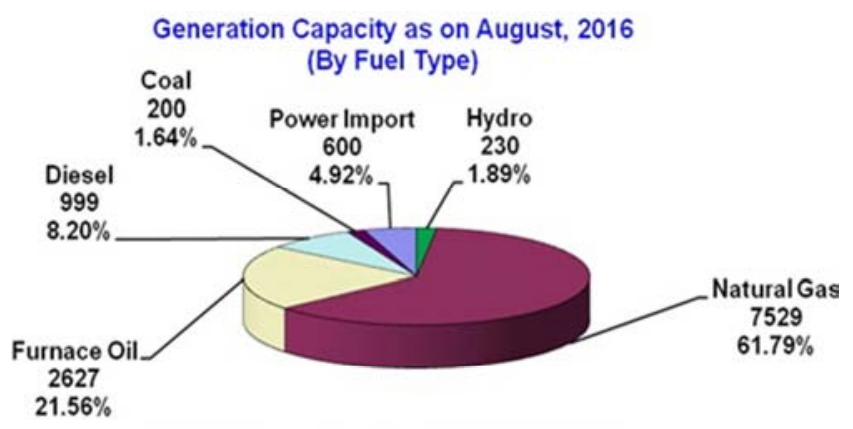

Total Generation Capacity: 12,185 MW

םHydro aNatural Gas QFurnace Oil םDiesel घCoal aPower Import

Figure 1. Electricity generation scenario of Bangladesh.

Bangladesh is situated between $20^{\circ} 34^{\prime}$ and $26^{\circ} 38^{\prime}$ North latitudes and $88^{\circ} 01^{\prime}$ and $92^{\circ} 41^{\prime}$ East longitudes bordered by the Bay of Bengal [17] at the south, Myanmar at the Southeast and India at the west, north and north-east with a land of $144,000 \mathrm{sq} \mathrm{km}$ area [18-19]. The geographical location makes it possible to harness the wind energy and convert it into electricity. If we can convert this huge amount of wind energy into electricity using wind turbine that will fulfill a significant percentage of national energy demand of Bangladesh. Before going for a large investment in renewable energy harvesting, it is wise to determine the LOCE for the feasibility study. LCOE is very useful tool in comparing technologies with different operating characteristics for electricity generation. LCOE of renewable energy can be highly sensitive to input assumptions, so consistent assumptions across technologies are important.

Till today, there are insignificant works that analyzed the LCOE of wind energy of Bangladesh. To develop a sustainable and economically viable means of electricity generation system from renewable source like wind energy, it is crucial to determine the LCOE of the energy conversion system. From this motivation, in this work, we predicted the LCOE at different location in the coastal area of Bangladesh. We also investigated the impacts of tower height and turbine blade diameter on the LCOE. For the calculation of LCOE, the wind velocity data at seven different locations has been taken which is represented in Table 1 [20]. In this research work, the wind velocity at $30 \mathrm{~m}$ and $35 \mathrm{~m}$ height has been calculated by using wind shear exponent [21-22] as follows:

Table 1. Average wind velocity of different coastal areas of Bangladesh throughout a year.

\begin{tabular}{|c|c|c|c|c|c|c|c|c|c|c|c|c|}
\hline \multirow{2}{*}{ Location } & \multicolumn{12}{|c|}{ Monthly wind velocity $(\mathrm{m} / \mathrm{s})$ at $25 \mathrm{~m}$ height } \\
\hline & Jan & Feb & Mar & Apr & May & Jun & Jul & Aug & Sep & Oct & Nov & Dec \\
\hline Patenga & 3.25 & 2.66 & 3.13 & 2.88 & 4.96 & 5.83 & 5.67 & 5.13 & 3.36 & 3.2 & 2.61 & 2.97 \\
\hline Cox's Bazar & 2.33 & 1.99 & 2.42 & 1.84 & 3.97 & 4.64 & 4.8 & 4.31 & 3.69 & 3.74 & 2.93 & 1.78 \\
\hline Teknaf & 1.99 & 1.90 & 2.26 & 1.65 & 3.09 & 3.26 & 4.33 & 4.03 & 3.46 & 3.30 & 2.29 & 1.44 \\
\hline Char Fassion & 2.80 & 2.69 & 3.54 & 3.29 & 4.81 & 5.76 & 5.22 & 5.17 & 3.34 & 3.70 & 3.8 & 3.9 \\
\hline Kuakata & 3.18 & 3.37 & 4.84 & 4.93 & 6.28 & 7.31 & 7.34 & 7 & 3.77 & 2.18 & 1.98 & 3.35 \\
\hline Kutubdia & 3.67 & 3.29 & 3.53 & 3.11 & 4.48 & 5.90 & 6.17 & 5.984 & 3.58 & 3.8 & 3.23 & 3.38 \\
\hline St. Martin & 5.08 & 4.71 & 4.29 & 3.58 & 5.75 & 5.96 & 5.33 & 5.96 & 4.79 & 4.17 & 3.79 & 4.08 \\
\hline
\end{tabular}




$$
v=v_{0}\left(\frac{h}{h_{\text {ref }}}\right)^{\alpha}
$$

Where $v_{0}$ : average wind speed at reference height, $v=$ wind speed at desired height, $h=$ desired height, $h_{\text {ref }}=$ reference height, wind shear exponent $\alpha$ changes along with the stability of atmosphere and in the coastal region of Bangladesh, $\alpha=0.15$ [23].

The cost of wind turbine and accessories are adopted from different companies of China [24-26]. The maintenance and other running cost are estimated as per market value of Bangladesh.

\section{Methodology of LCOE Calculation}

The LCOE is a common term to compare power generating technologies. The full life-cycle costs (fixed and variable) of a power generating technology per unit of electricity $(\mathrm{kWh})$ are often called levelized costs of electricity (LCOE) or levelized energy costs (LEC). This is very acceptable in renewable industries as it allows comparing conventional plants with renewable sources like wind, solar power, hydro, etc even though they have different cost structures. For renewable sources fixed costs are often very high, and variable costs are negligible. On the other hand, conventional technologies have different fixed-to-variablecosts ratios [27]. LCOE of renewable technologies and conventional technologies should be compared to understand the competitively and economical sustainability.

The LCOE can be estimated from the following simplified equation.

$$
\begin{aligned}
L C O E & =\frac{\text { Life Cycle Cost }}{\text { Life Cycle Energy Production }} \\
L C O E & =\frac{I_{t}+\sum_{t=1}^{n} \frac{M_{t}+F_{t}}{(1+r)^{t}}}{\sum_{t=1}^{n} \frac{E_{t}}{(1+r)^{t}}}
\end{aligned}
$$

Where, $I_{t}$ : initial investment expenditure, $M_{t}$ : Operation and maintenance expenditure in year $t, F_{t}$ : fuel expenditure in year $t, E_{t}$ : electricity generation in year $t, r$ : discount rate and $n$ : lifetime of the wind turbine system.

In this paper we have calculated LCOE of wind energy based on two important assumptions. For simplicity we have ignored discount rate and the electricity price remains stable throughout the lifetime of the electricity generation project. The prices of wind turbine systems adopted from different companies are listed in Table 2 and Table 3.

\section{Result and Discussion}

In this work, we have calculated the LCOE for wind energy at seven different location of Bangladesh. We have also investigated the dependence of LCOE on blade diameter, tower height and on and off grid conditions. In our calculation we considered only horizontal axis wind turbines because, this type of turbine occupies less space. As Bangladesh is a densely populated country so this type of wind turbine is more suitable for Bangladesh. Though vertical axis turbine can operate at a very low speed but due to inadequate space, horizontal axis turbine suits best for our purpose. Fig. 2 shows the wind velocity in different locations throughout the year.

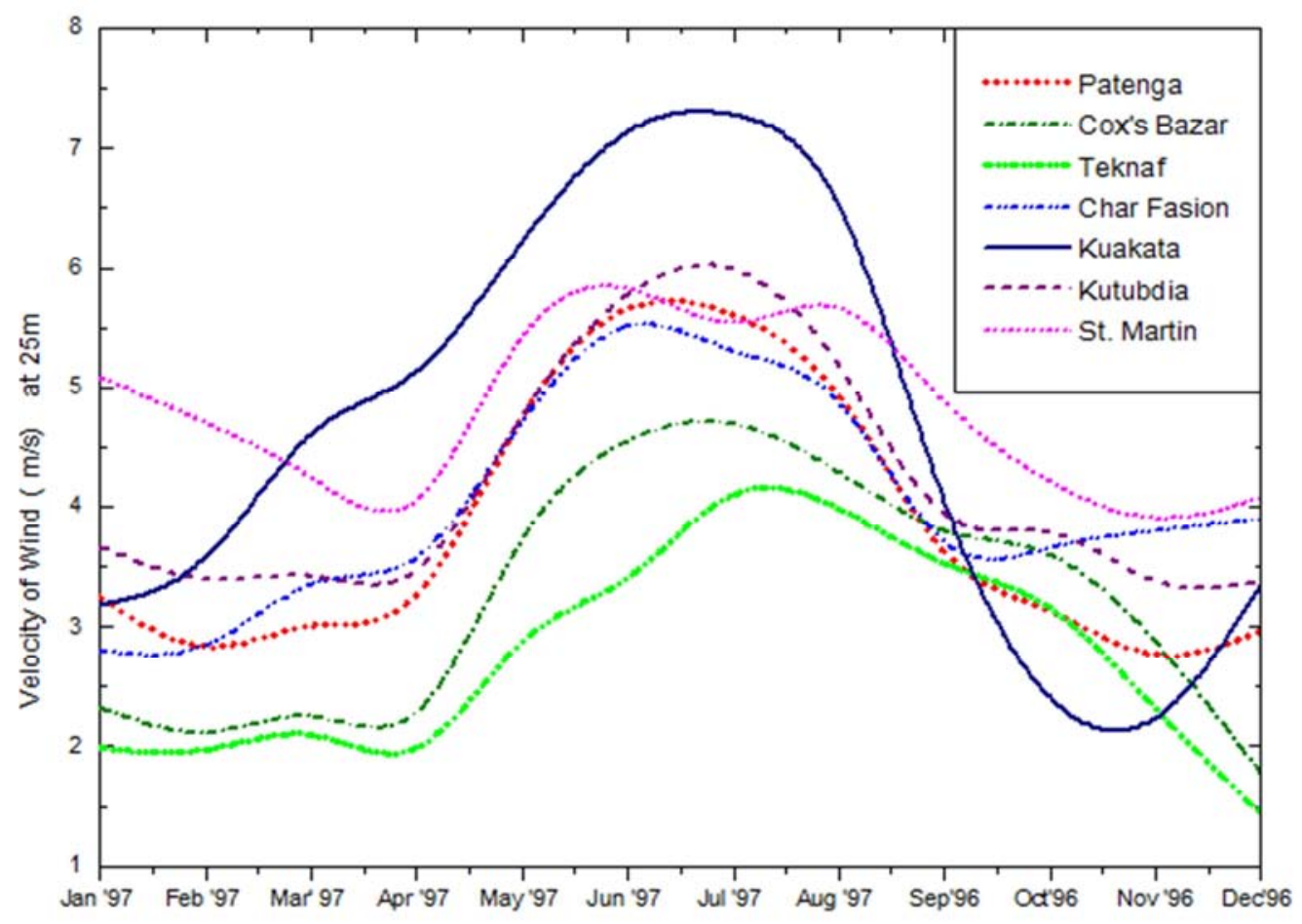

Figure 2. Wind velocities throughout a year in different coastal area of Bangladesh. 
Table 2. Cost distribution of wind turbine system (Off Grid) for 25 years.

\begin{tabular}{llll}
\hline & Company 1 50kW & Company 2 100kW & Company 3 100kW \\
\hline Blade Diameter & $15 \mathrm{~m}$ & $21 \mathrm{~m}$ & $22 \mathrm{~m}$ \\
Installation Cost(USD) & 1433670 & 155561 & 172000 \\
Repair and Maintenance Cost for 25 years(USD) & 90000 & 90000 & 90000 \\
Total Cost for 25 years(USD) & 233370 & 245561 & 262000 \\
Total Cost for 25 years (BDT) & 18669564 & 19644907 & 20960000 \\
\hline
\end{tabular}

Table 3. Cost distribution of wind turbine system (Grid) for 25 years.

\begin{tabular}{llll}
\hline & Company 1 50kW & Company 2 100kW & Company 3 100kW \\
\hline Blade Diameter & $15 \mathrm{~m}$ & $21 \mathrm{~m}$ & $22 \mathrm{~m}$ \\
Installation Cost (USD) & 144758 & 156194 & 20200 \\
Repair and Maintenance Cost for 25 years(USD) & 90000 & 90000 & 90000 \\
Total Cost for 25 years(USD) & 234758 & 246194 & 292000 \\
Total Cost for 25 years (BDT) & 18780676 & 19695547 & 23360000 \\
\hline
\end{tabular}

It is noticed from the figure that the highest wind velocity in is found in Kuakata. It is also noticed that the wind velocity in St. Martin is moderately good compared with other locations. Thus, it may be argued that among these locations most suitable wind energy harvesting is suitable in Kuakata and St Martin. The impact of turbine blade diameter on the LCOE is depicted in Fig. 3.

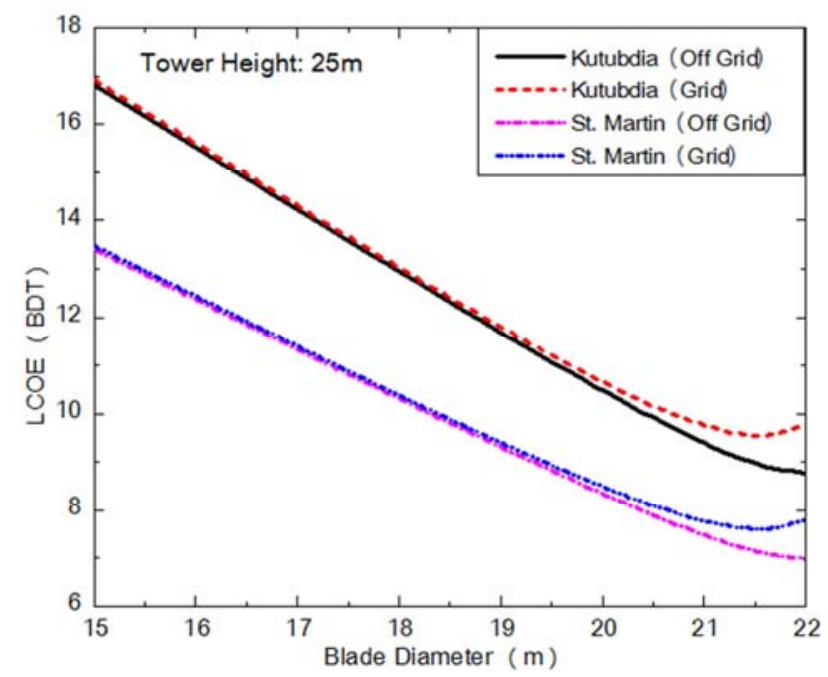

Figure 3. Dependence of LCOE of wind energy on the blade diameter.

It is found that the LCOE significantly depends on the blade diameter. It is implicit that larger blade diameter results lower LCOE. Fig.4 describes the effects of tower height on the LCOE of wind energy.

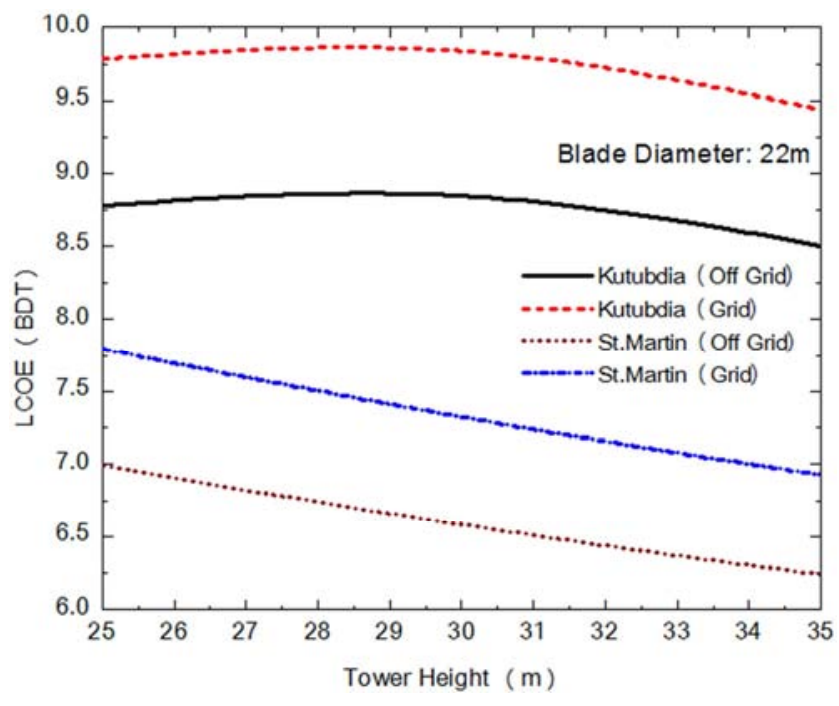

Figure 4. Dependence of LCOE of wind energy on tower height.

It is noticed that the tower height has a very insignificant effect on LCOE. Both in Kutubdia and St Martin, only BDT 1 difference between off-grid and grid connected wind turbine systems. Thus it may be stated that in the coastal area, moderate height should be considered for installing the wind turbine system. Fig.5 shows the final LCOE at seven different locations in the coastal area for off-grid system for two tower heights. 


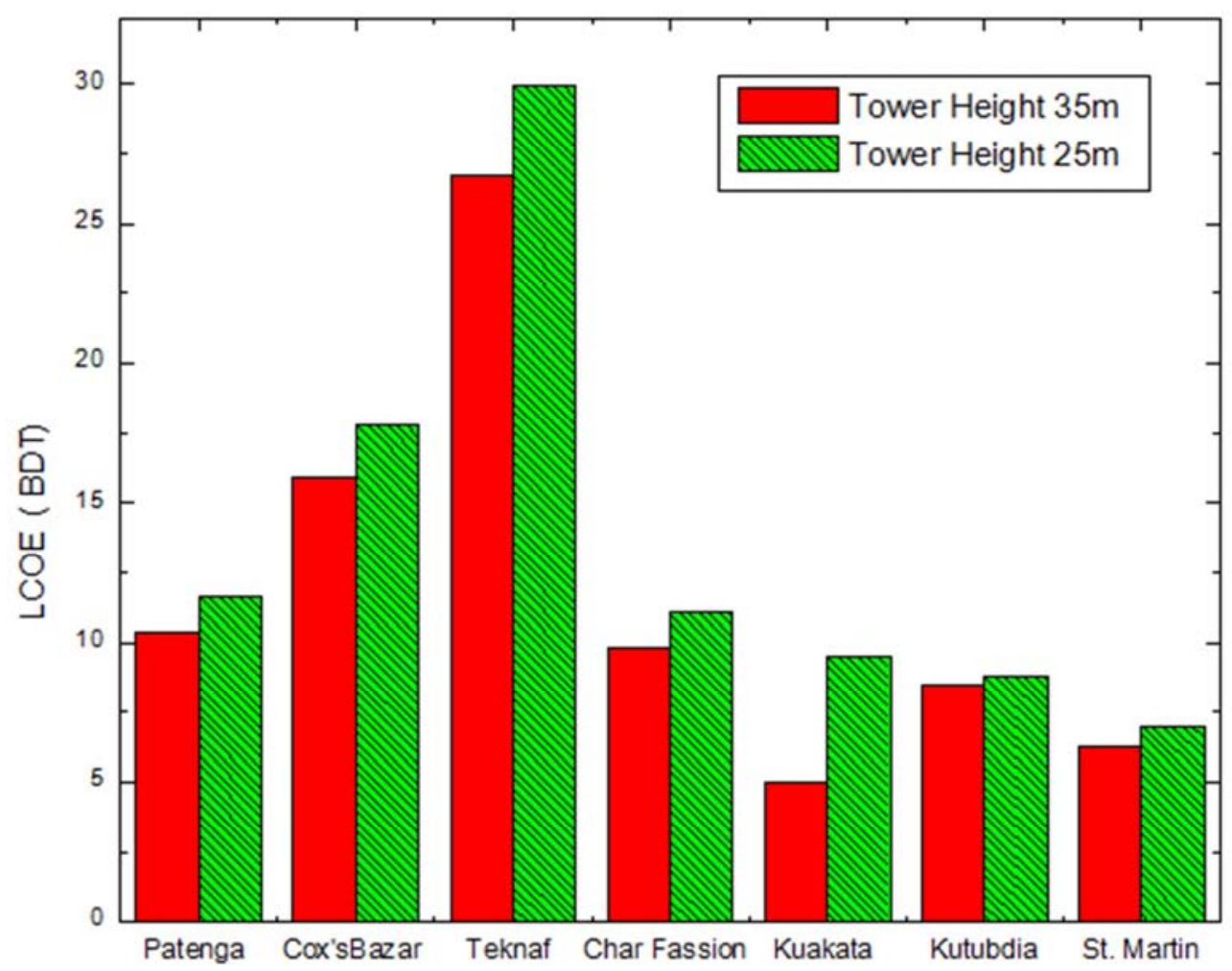

Figure 5. LCOE of wind energy at different coastal areas of Bangladesh for off-grid system.

It is noticed that the lowest LCOE is at Kuakata (BDT 5) and height at Teknaf (BDT 27) for a tower height of $35 \mathrm{~m}$.

\section{Conclusions}

In this paper, the LCOEs of wind energy systems (both offgrid and on-grid) have been calculated for seven different locations in the coastal area of Bangladesh. The base data of wind velocity has been taken from literature. The prices of different components of wind turbine systems have taken from different vendors. Based on these data, LCOE at seven different locations have been calculated. The effects of blade diameter and tower height have also been investigated. It is found that the best suitable location for wind energy harvesting in the coastal area is Kuakata and St Martin. It is also found that for a grid-connected system, LCOE drastically falls for a blade diameter shift from $15 \mathrm{~m}$ to $21.5 \mathrm{~m}$. However, after that point the LCOE again has a tendency to increase with blade diameter. Thus for the selected locations, the ideal blade diameter for grid connected system is $21.5 \mathrm{~m}$.

\section{References}

[1] IEA, "Energy technology perspectives: scenarios and strategies to 2020 " available:

http://www.iea.org/textbase/nppdf/free/2008/weo2008.pdf (2008).

[2] M. R. Islam, S. Mekhilef and R. Saidur, "Progress and recent trends of wind energy technology," Renewable and Sustainable Energy Reviews, vol. 21, (2013), pp.456-468.
[3] A. Al-Karaghouli, and L. L. Kazmerski. "Energy consumption and water production cost of conventional and renewableenergy-powered desalination processes." Renewable and Sustainable Energy Reviews, vol. 24 (2013). pp. 343-356.

[4] M. S. Alam, E. Kabir, M. M. Rahman, and M. A. K. Chowdhury. "Power sector reform in Bangladesh: Electricity distribution system.” Energy vol. 29, no. 11 (2004), pp. 1773-1783.

[5] B. D. Rahmatullah. "System Loss in Power Sector: A major challenge for economic sustainability." Dhaka: Engineering News, Institution of Engineers Bangladesh (2001), p. 40.

[6] http://www.esrl.noaa.gov/gmd/ccgg/trends/ff.html.

[7] S. McDonald, and D. L. Vander Zwaag. "Renewable Ocean Energy and the International Law and Policy Seascape: Global Currents, Regional Surges." Ocean Yearbook Online 29, No.1 (2015), pp. 299-326.

[8] V. Fthenakis, J. E. Mason, K. Zweibel, "The technical, geographical, and economic feasibility for solar energy to supply the energy needs of the US", Energy Policy vol. 37 (2009), pp. 387-399.

[9] B. K. Sovacool, C. Watts, "Going Completely Renewable: Is It Possible (Let Alone Desirable?)", The Electricity Journal, vol.22 (2009), pp. 95-111.

[10] K. Branker, M. J. M. Pathak, and J. M. Pearce. "A review of solar photovoltaic levelized cost of electricity." Renewable and Sustainable Energy Reviews, vol. 15, No 9 (2011), pp. 4470-4482.

[11] S. M. N. Uddin, M. Bodrudduza, B. M. Rahman, and M. F. Khan, M. F. "RET Screen based feasibility study on the prospect of wind power generation along the coastal region of Chittagong, Bangladesh." 4th International Conference on the Development in the in Renewable Energy Technology (ICDRET), Dhaka, Bangladesh. (2016). 
[12] S. Rashid, S. Rana, S. K. A. Shezan, S. AB Karim, and S. Anower. "Optimized design of a hybrid PV-wind-diesel energy system for sustainable development at coastal areas in Bangladesh." Environmental Progress \& Sustainable Energy. (2016).

[13] S. A. Shezan, A. Z. M. Salahuddin, M. Farzana, and A. Hossain. "Techno-economic analysis of a hybrid PV-winddiesel energy system for sustainable development at coastal areas in Bangladesh." 4th International Conference on the Development in the in Renewable Energy Technology (ICDRET), Dhaka, Bangladesh. (2016).

[14] https://www.cia.gov/library/publications/the-worldfactbook/geos/bg.html\#People.

[15] http://www.bpdb.gov.bd/bpdb/index.php?option=com_content $\&$ view $=$ article \&id $=5 \&$ Itemid $=6$.

[16] http://www.bpdb.gov.bd/bpdb/index.php?option=com_content $\&$ view $=$ article $\&$ id $=7 \&$ Itemid $=8$.

[17] M. Murshed, M. Y. Arafat, and M. A. Razzak, "Analysis of air foils and design of blades for a low-speed 250W horizontal axis wind turbine suitable for coastal areas of Bangladesh." In Development in the in Renewable Energy Technology (ICDRET), (2016) 4th International Conference on the IEEE.

[18] M. J. Khan, M. T. Iqbal, and S. Mahboob. "A wind map of Bangladesh," Renewable Energy, vol. 29, No 5 (2004), pp. 643-660.

[19] A. N. M. M. I Mukut, M. Q. Islam, and M. M. Alam. "Prospect of Wind Energy in the Coastal Belt of Bangladesh."
The Pacific Journal of Science and Technology, vol. 9, No 2 (2008), pp. 442-451.

[20] M. G. K. Khan, T. Rahman, and M. M. Alam. "Wind Energy in Bangladesh: Prospects and Utilization Initiatives". 3rd International Conference on Electrical \& Computer Engineering ICECE. Dhaka, Bangladesh (December 2004). pp. 28-30.

[21] S. Ahmmed, and M. Q. Islam. "Wind power for rural areas of Bangladesh". 3rd International Conference on Electrical \& Computer Engineering, (ICECE) (December, 2004), pp. 192197.

[22] M. L. Kubik, J. C. Phil, and C. Hunt. "Using meteorological wind data to estimate turbine generation output: a sensitivity analysis." World Renewable Energy Congress-Sweden; Linköping; Sweden. (May, 2011), pp. 4074-4081.

[23] M. Murshed, M. Y. Arafat, and M. A. Razzak, "Analysis of air foils and design of blades for a low-speed 250W horizontal axis wind turbine suitable for coastal areas of Bangladesh." 4th International Conference on the Development in the in Renewable Energy Technology (ICDRET), Dhaka, Bangladesh (2016).

[24] http://www.tanfon.com/.

[25] http://www.hummerwindenergy.com.

[26] http://www.changfengenergy.com/?lang=en.

[27] F. Ueckerdt, L. Hirth, G. Luderer, and O. Edenhofer, "System LCOE: What are the costs of variable renewables?" Energy, vol. 63, (2013), pp. 61-75. 